\title{
Association between blood pressure and retinal arteriolar and venular diameters in Chinese early adolescent children, and whether the association has gender difference: a cross-sectional study
}

Yuan He${ }^{1}$, Shi-Ming Li ${ }^{1}$, Meng-Tian Kang ${ }^{1}$, Luo-Ru Liư ${ }^{2}$, He Li ${ }^{2}$, Shi-Fei Wei ${ }^{1}$, An-Ran Ran ${ }^{1}$, Ningli Wang ${ }^{1 *}$ and the Anyang Childhood Eye Study Group

\begin{abstract}
Background: To establish the independent association between blood pressure (BP) and retinal vascular caliber, especially the retinal venular caliber, in a population of 12-year-old Chinese children.

Methods: We have examined 1501 students in the 7th grade with mean age of 12.7 years. A non-mydriatic fundus camera (Canon CR-2, Tokyo, Japan) was used to capture $45^{\circ}$ fundus images of the right eyes. Retinal vascular caliber was measured using a computer-based program (IVAN). BP was measured using an automated sphygmomanometer (HEM-907, Omron, Kyoto, Japan).

Results: The mean retinal arteriolar caliber was $145.3 \mu \mathrm{m}$ (95\% confidence interval [Cl], 110.6-189.6 $\mu \mathrm{m}$ ) and the mean

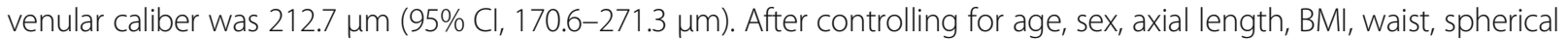
equivalent, birth weight, gestational age and fellow retinal vessel caliber, children in the highest quartile of BP had significantly narrower retinal arteriolar caliber than those with lower quartiles $(P$ for trend $<0.05)$. Each $10-\mathrm{mmHg}$ increase in BP was associated with narrowing of the retinal arterioles by $3.00 \mu \mathrm{m}$ (multivariable-adjusted $P<0.001$ ), and the results were consist in three BP measurements. The association between BP measures and retinal venular caliber did not persist after adjusting for fellow arteriolar caliber. And there was no significant interaction between BP and sex, age, BMl, and birth status.
\end{abstract}

Conclusions: In a large population of adolescent Chinese children, higher BP was found to be associated with narrower retinal arterioles, but not with retinal venules. Sex and other confounding factors had no effect on the relationship of BP and retinal vessel diameter.

Keywords: Hypertension, Adolescents, Retinal arteriolar diameter, Retinal venular diameter, Blood pressure

\footnotetext{
* Correspondence: xiaowwnnll@163.com

${ }^{1}$ Beijing Tongren Eye Center, Beijing Tongren Hospital, Beijing

Ophthalmology \& Visual Science Key Lab, Beijing Institute of Ophthalmology,

Capital Medical University, Beijing, China

Full list of author information is available at the end of the article
}

(c) The Author(s). 2018 Open Access This article is distributed under the terms of the Creative Commons Attribution 4.0 International License (http://creativecommons.org/licenses/by/4.0/), which permits unrestricted use, distribution, and reproduction in any medium, provided you give appropriate credit to the original author(s) and the source, provide a link to the Creative Commons license, and indicate if changes were made. The Creative Commons Public Domain Dedication waiver (http://creativecommons.org/publicdomain/zero/1.0/) applies to the data made available in this article, unless otherwise stated. 


\section{Background}

Major component of the circulatory system is composed of the microcirculation, which plays an important role in maintaining cardiovascular health. There is a widespread influence of blood pressure (BP) on the structure and function of microcirculation system. Early in the late nineteenth century, Marcus Gunn had put forward the statement that there were associations between microvascular abnormalities and cardiovascular diseases [1].

The retina is a unique structure of the eyes, where the in vivo microcirculation can be directly visualized and monitored non-invasively. Retinal microcirculation shares the same anatomic architecture and physiological feature with other terminal organs elsewhere in the body [2]. These characteristics increase its utility as a tool to study the clinical performance of microvascular diseases. Recently, with the improvement of retinal imaging particularly the computer-assistant analysis techniques from digital retinal images [3], plenty of epidemiological studies in adult populations have displayed that abnormal changes in retinal vascular caliber (predominantly retinal arteriolar and venular caliber) are closely associated with some systemic vascular abnormalities such as cardiovascular risk factors [4], hypertension [5], coronary heart disease [6], risk of diabetes and stroke [7], cerebral infarcts and white matter lesions [8], and renal disease [9], independent of other risk factors.

Despite increasing data on the risk prediction of retinal vascular caliber measurement in different population-based studies, there had been still some controversial opinions on association between retinal vascular changes and BP, especially for the retinal venular changes. Understanding the impacts of $\mathrm{BP}$ and changes to the retinal microvasculature in persons with different background is an important aspect of the study on microcirculation disease. Children are generally free of many systemic conditions and eye diseases (such as glaucoma or diabetic retinopathy, etc.) that could bring about confounding effects on observed associations. High BP in children and adolescents is more and more common in western countries [10], and BP levels and prevalence of hypertension has increased dramatically among children and adolescents in China [11]. It is encouraging that there are some studies on the association of BP and retinal vessel caliber in children recently, but substantial data on children group are still needed to provide the reference data.

In this study, we investigated the independent association between blood pressure measures and changes to the retinal microvasculature in a relatively large population of 12-year-old Chinese children. This study also assessed the potential modifying influences of age, BMI, birth parameters, especially sex, on the associations between BP and retinal vessel caliber.

\section{Methods}

\section{Study population}

The Anyang Childhood Eye Study (ACES) is a school-based cohort study designed to observe the occurrence and development of myopia as well as other diseases in school children living in Anyang urban area, Henan Province, Central China. Detailed methodology of the study has been previously described [12]. In briefly, 1501 students in 7th grade average aged 12.7 years have been examined from October 2011 to December 2011. The flowchart of participants included in the present study was shown in Fig. 1. Ethics approval was obtained from the institutional review board of Beijing Tongren Hospital, Capital Medical University, and followed the tenets of the declaration of Helsinki. Informed written consent was obtained from at least one parent. Verbal assent was obtained from each child.

\section{Retinal photography and measurement of retinal vascular caliber}

The children were examined at health examination station of the Anyang Eye Hosptial. A non-mydriatic fundus camera (Canon CR-2, Tokyo, Japan) was used to capture $45^{\circ}$ fundus images centering on optic disc and macular area of children's right eyes by a well-trained operator [12]. Children with abnormal fundus images would also undergo left eye measurements, and we analyzed one picture for each child.

According to a standardized protocol described previously [3], the computer-imaging program (IVAN, University of Wisconsin, Madison, WI) was used to measure calibers of all retinal arterioles and venules located in zone 0.5 to 1 disc diameter from the optic disc margin (zone B). The program automatically combined vessel diameters from the six largest arterioles and six largest venules into a pair of indices. The central retinal arteriolar and venular equivalents (CRAE and CRVE) represent the average arteriolar and venular caliber for each eye, respectively. One grader masked to children's identity and characteristics performed all measurements. Before starting the measurement, 50 randomly selected retinal images were repeatedly measured by the grader with an interval of 2 weeks. The reliability was high with intraclass correlation coefficients of 0.85 for arteriolar caliber and 0.97 for venular caliber.

\section{Blood pressure measurement}

Blood pressure of children was measured in a seated position after 5 min of rest using an automated sphygmomanometer (HEM-907, Omron, Kyoto, Japan) with appropriate cuff size (bladder length $\approx 80 \%$ and width at least $40 \%$ of the arm circumference, covering the upper arm but not obscuring the antecubital fossa). Systolic and diastolic blood pressure (SBP and DBP, respectively) 


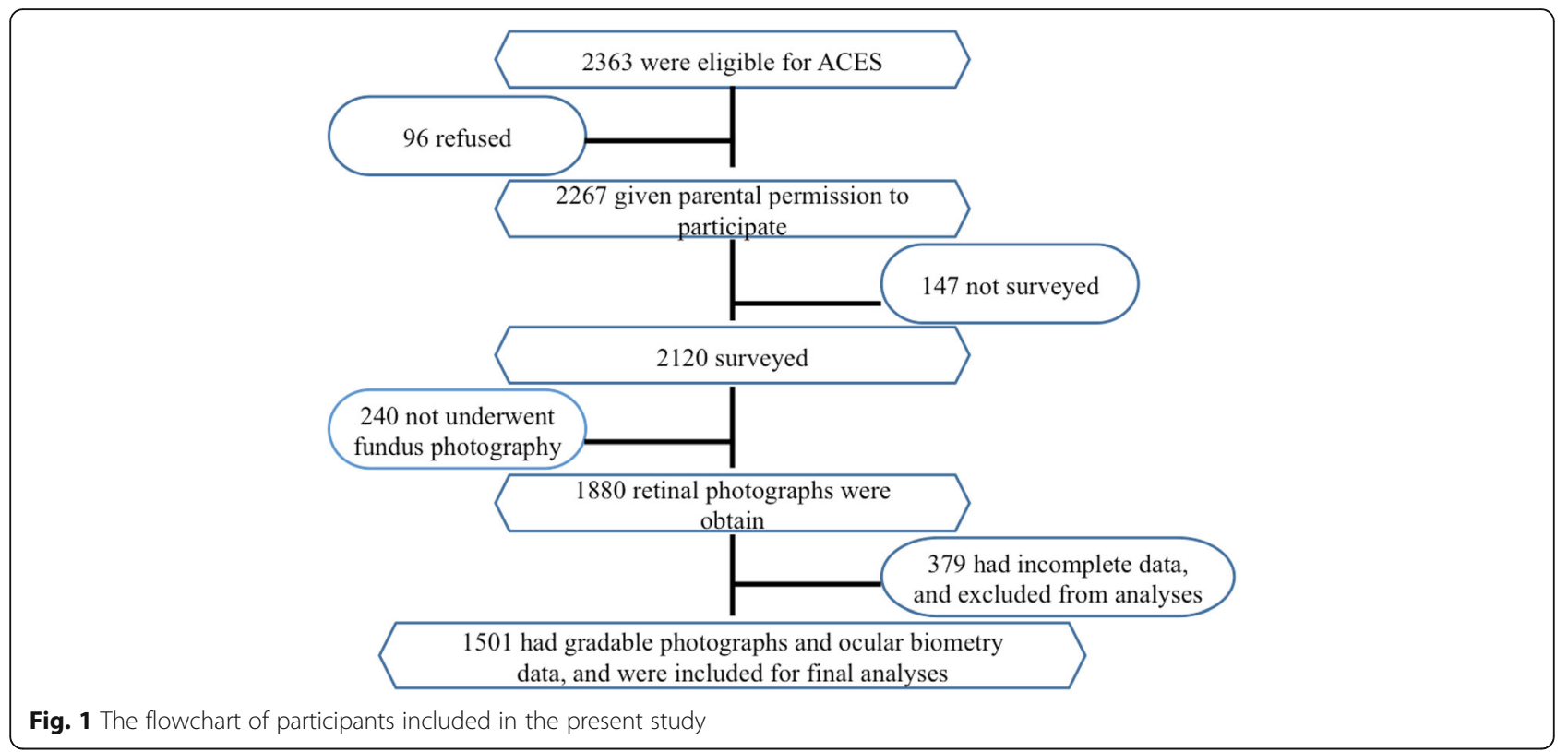

readings were taken. Two readings were taken 5 min apart and averaged for analysis. Mean arterial blood pressure (MABP) was computed as $2 / 3$ of the diastolic plus $1 / 3$ of the systolic value.

\section{Other measurements}

Any abnormality of anterior segment (any abnormalities of the anterior segment of the eye, such as corneal leukoplakia, cataract, pupil abnormalities, iris anterior adhesion, etc.) was observed and recorded using a slit-lamp (YZ5J, 66 Vision Tech Co, Suzhou, China). Cycloplegic spherical equivalent refraction was measured using an autorefractor (HRK7000 A, Huvitz, Gunpo, South Korea) with three readings taken and averaged. An optical coherence biometry (IOL-master 1322-734, Carl Zeiss Meditec AG, Jena, Germany) was applied to evaluate the optical axial length $(\mathrm{AL})$ value along the visual axis (line connecting the fixation point to the fovea, specifically from the anterior surface of the cornea to the retinal pigment epithelium layer of the fovea), with five repeated measurements taken and averaged. Height and weight were measured using an automatic and professional integrated set. Body mass index (BMI) was calculated as weight $/$ height $^{2}\left(\mathrm{~kg} / \mathrm{m}^{2}\right)$. Waist circumference was measured with a tape measure and was defined as the narrowest part of the student's trunk. Birth information including gestational weeks, birth weight and birth length were collected by administrating questionnaires to the participating students' parents.

\section{Statistical analysis}

SAS (v9.3, SAS Institute Inc., Cary, NC, USA) was used to perform statistical analysis. BP was categorized into quartiles as well as being analyzed as a continuous variable (i.e. each $10 \mathrm{mmHg}$ increase). The retinal arteriolar, venular calibers, and arteriolar to venular ratio (AVR) were compared across blood pressure quartiles based on three models, Model 1 was analyzed without any adjustment, Model 2 adjusted for multivariate variables (age, sex, axial length, BMI, waist, spherical equivalent, birth weight, and gestational age) and then Model 3 adjusted additionally for fellow retinal vessel diameter. The test of trend was determined by regarding quartiles of $\mathrm{BP}$ as continuous ordinal variables. Multiple linear regressions were used to estimate the absolute changes in retinal arteriolar and venular caliber for a $10-\mathrm{mmHg}$ increase in SBP, DBP, and MABP. Potential modifiers were examined in stratified analyses of age, sex, BMI, and birth parameters. All probabilities quoted are two-sided, and a significant $P$ value was defined as $<0.05$.

\section{Results}

Table 1 shows the study characteristics of the children included for crosss-sectional analyses. Compared with boys, girls had higher systolic and mean arterial blood pressure, higher waist and BMI, and had less myopia and longer axial length.

Table 2 shows the mean retinal vascular caliber and AVR by quartiles of systolic, diastolic and mean arterial blood pressure in three different models. Children with highest quartile of BP were more likely to have narrower retinal arteriolar caliber than those in the lowest quartile after multivariable-adjustment (all $P<0.01$ ), with a mean difference of 6-7 $\mu \mathrm{m}$ between the highest and lowest quartiles, and the results were consistent for three BP measurements. As for retinal venular diameter, in Model 
Table 1 Basic characteristics of the children included in the study

\begin{tabular}{llll}
\hline Characteristics & Male & Female \\
& $(n=792)$ & $(n=709)$ & $P$ \\
\hline Age (year) & $12.66(0.50)$ & $12.73(0.49)$ & $\mathbf{0 . 0 0 4}$ \\
Spherical equivalent refraction (diopters) & $-1.78(2.08)$ & $-1.32(2.02)$ & $<\mathbf{0 . 0 0 1}$ \\
Axial length (mm) & $23.93(1.01)$ & $24.35(1.09)$ & $<\mathbf{0 . 0 0 1}$ \\
Systolic blood pressure (mm Hg) & $104.55(10.87)$ & $107.36(10.35)$ & $\mathbf{< 0 . 0 0 1}$ \\
Diastolic blood pressure (mm Hg) & $65.35(7.57)$ & $65.45(7.21)$ & 0.758 \\
Mean arterial blood pressure $(\mathrm{mm} \mathrm{Hg)}$ & $78.42(8.23)$ & $79.41(7.63)$ & $\mathbf{0 . 0 0 5}$ \\
BMl $\left(\mathrm{kg} / \mathrm{m}^{2}\right)$ & $19.32(3.22)$ & $20.28(3.91)$ & $<\mathbf{0 . 0 0 1}$ \\
Waist $(\mathrm{cm})$ & $69.04(7.84)$ & $71.92(10.14)$ & $<\mathbf{0 . 0 0 1}$ \\
\hline
\end{tabular}

Data are mean (SD). BMI body mass index; Significant $p$ values are bolded. Significant $p$ values are bolded

1, children with higher BP had significantly narrower CRVE $(P<0.001$ for trend for three BP measurements), and in Model 2, only children with higher SBP were found to have narrower CRVE than those with lower SBP $(P=0.038$ for trend), however, this association did not persist after adjusting for fellow vessel caliber. In Model 1 and Model 2, children with higher BP quartiles had consistently and significantly narrower AVR $(P<$ 0.001 for trend), and the results were consistent for three BP measurements.

Table 3 shows the multivariable linear regression between retinal vascular caliber and BP. In model 1 and model 2, for each 10-mmHg increase in SBP, DBP and MABP, CRAE decreased by $3.07-4.40 \mu \mathrm{m}(P<0.001)$ and CRVE decreased by $1.47-2.69 \mu \mathrm{m}(P<0.001)$. In model 3 adjusted for fellow vessel caliber additionally, each $10-\mathrm{mmHg}$ increase in BP was associated with 2.34$3.47 \mu \mathrm{m}$ decrease in retinal arteriolar caliber $(P<0.001)$, but no significant change in CRVE $(p>0.42)$ was observed. AVR decreased by 0.010 to 0.014 for every $10-\mathrm{mmHg}$ increase in BP in Model 1, Further adjustment for age, gender, axial length, BMI, waist, spherical equivalent, birth weight and gestational age had no impact on the magnitude of this effect (AVR reduction 0.007 to 0.012 ).

Subgroup analysis stratified by potential effect modifiers was presented in Tables 4, 5 and 6. Associations were consistent across subgroups stratified by age, sex, BMI, and birth parameters.

It is worth noting that, there were no significant interactions between sex, and BP on retinal vessel diameters. The impact of $\mathrm{BP}$ on the diameters of retinal vessels showed no gender differences between boys and girls. In model 2, each $10-\mathrm{mmHg}$ increase in BP was associated with 3.41-4.91 $\mu \mathrm{m}(P<0.001)$ and $2.73-3.89 \mu \mathrm{m}(P<$ 0.001) decrease in CRAE for boys and girls respectively, and in model 3 , the decrease of CRAE reduced to 2.57$3.81 \mu \mathrm{m}(P<0.001)$ and $2.12-3.12 \mu \mathrm{m}(P<0.001)$ for boys and girls respectively (Table 4 ). And for CRVE, each 10-mmHg increase in BP resulted in $2.03-2.68 \mu \mathrm{m}$ $(P<0.05)$ decrease for boys and 2.15-2.76 $\mu \mathrm{m}(P<0.05)$ decrease for girls in model 2, but when CRAE was additionally adjusted in model 2 , there is no significant association between BP and CRVE in either boys nor girls, which was consistent in three BP measurements (Table 5).

\section{Discussion}

In this population of 12-year-old Chinese children, we found that increasing blood pressure was significantly associated with narrowing retinal arteriolar caliber and smaller AVR, but not with retinal venular caliber. After controlling for age, gender, axial length, BMI, waist, spherical equivalent, birth parameters and fellow retinal vessel, each $10-\mathrm{mmHg}$ increase in $\mathrm{BP}$ was associated with an approximate 3 4 $\mu \mathrm{m}$ reduction in CRAE, and the changes were consistent of three BP measurements. The similar pattern and magnitude of change were also found in the relationship of BP with CRVE prior of taking confounding fellow arteriolar diameter into account, but after the fellow vessel were further adjusted, the change no longer had significant difference. And there was no significant interaction between BP and age, sex, BMI and birth status.

Both cross-sectional and longitudinal studies had provided substantial evidence that there is significant association between elevated blood pressure or hypertension and narrower central retinal arteriole caliber in adult populations [13-19]. However, there is conflicting evidence on retinal venular diameter as marker related to hypertension. Some studies [16, 18-22] suggested that retinal venular widening may be independently associated with risk of hypertension, others $[15,19$, 23-25] had found no association, whereas some other researchers announced that both retinal venular and arteriolar caliber were inversely related to blood pressure, independent of age, gender, and smoking [26]. 


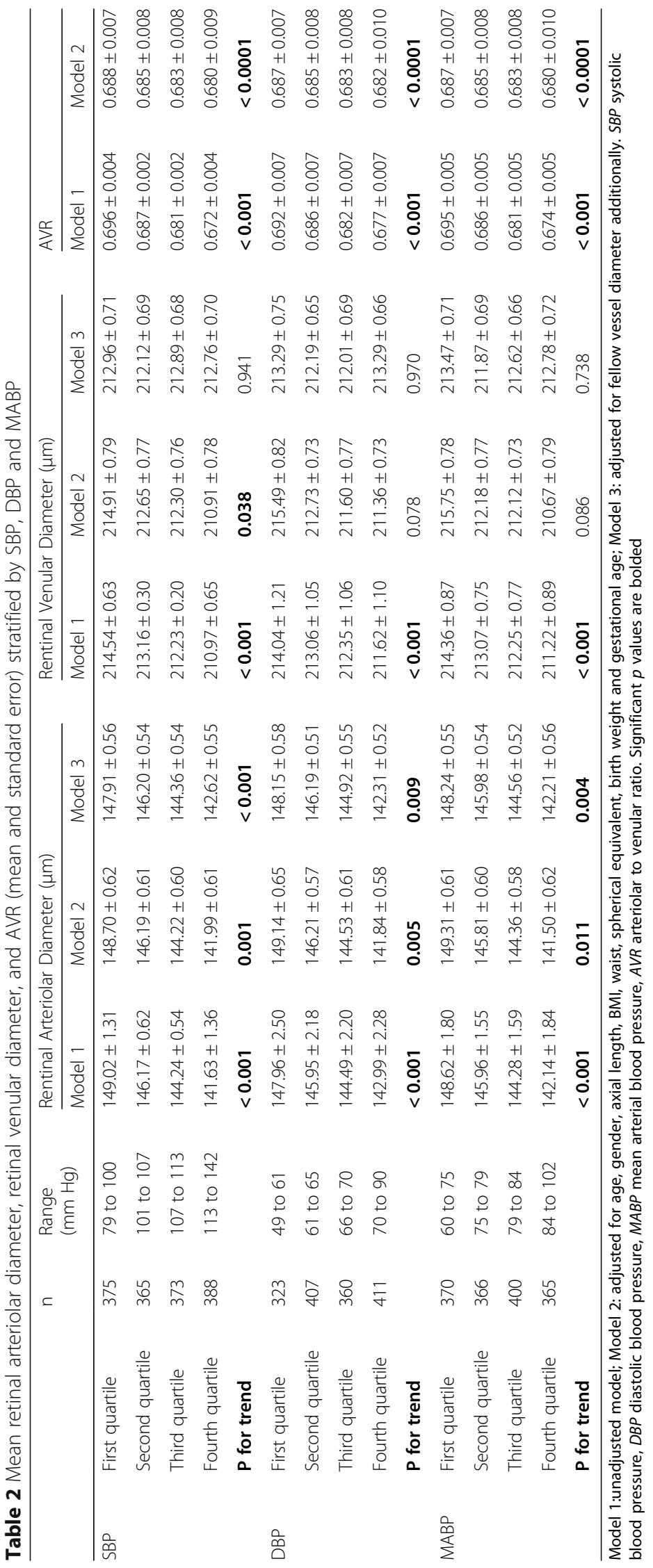


Table 3 Multivariate Linear Regression Models of Retinal Vascular Caliber and Blood Pressure

\begin{tabular}{|c|c|c|c|c|c|c|}
\hline & \multicolumn{2}{|c|}{ Retinal arteriolar diameter $(\mu \mathrm{m})$} & \multicolumn{2}{|c|}{ Retinal venular diameter $(\mu \mathrm{m})$} & \multicolumn{2}{|l|}{ AVR } \\
\hline & Mean $(95 \% \mathrm{Cl})$ & $P$ & Mean $(95 \% \mathrm{Cl})$ & $P$ & Mean $(95 \% \mathrm{Cl})$ & $P$ \\
\hline \multicolumn{7}{|l|}{ SBP } \\
\hline Model 1 & $-3.23(-3.96$ to -2.52$)$ & $<0.001$ & $-1.57(-2.50$ to -0.63$)$ & $<0.001$ & $-0.01(-0.013$ to -0.007$)$ & $<0.001$ \\
\hline Model 2 & $-3.07(-3.79$ to -2.34$)$ & $<0.001$ & $-2.06(-2.97$ to -1.15$)$ & $<0.001$ & $-0.007(-0.010$ to -0.004$)$ & $<0.001$ \\
\hline Model 3 & $-2.34(-3.00$ to -1.69$)$ & $<0.001$ & $-0.34(-1.18$ to 0.50$)$ & 0.428 & - & - \\
\hline \multicolumn{7}{|l|}{ DBP } \\
\hline Model 1 & $-3.85(-4.88$ to -2.82$)$ & $<0.001$ & $-1.47(-2.78$ to -0.15$)$ & $<0.001$ & $-0.013(-0.017$ to -0.009$)$ & $<0.001$ \\
\hline Model 2 & $-4.02(-4.96$ to -3.08$)$ & $<0.001$ & $-2.34(-3.53$ to -1.15$)$ & $<0.001$ & $-0.011(-0.015$ to -0.007$)$ & $<0.001$ \\
\hline Model 3 & $-3.20(-4.05$ to -2.35$)$ & $<0.001$ & $-0.06(-1.16$ to 1.03$)$ & 0.909 & - & - \\
\hline \multicolumn{7}{|l|}{ MABP } \\
\hline Model 1 & $-4.37(-5.35$ to -3.39$)$ & $<0.001$ & $-1.84(-3.11$ to -0.56$)$ & $<0.001$ & $-0.014(-0.019$ to -0.010$)$ & $<0.001$ \\
\hline Model 2 & $-4.40(-5.34$ to -3.47$)$ & $<0.001$ & $-2.69(-3.88$ to -1.50$)$ & $<0.001$ & $-0.012(-0.016$ to -0.007$)$ & $<0.001$ \\
\hline Model 3 & $-3.47(-4.31$ to -2.62$)$ & $<0.001$ & $-0.21(-1.31$ to 0.89$)$ & 0.712 & - & - \\
\hline
\end{tabular}

Model 1:unadjusted model; Model 2: adjusted for age, gender, axial length, BMI, waist, spherical equivalent, birth weight and gestational age; Model 3: adjusted for fellow vessel diameter additionally. SBP systolic blood pressure, DBP diastolic blood pressure, MABP mean arterial blood pressure, AVR arteriolar to venular ratio. Significant $p$ values are bolded

In addition, smaller retinal arteriolar caliber was also found to be associated with current alcohol consumption, greater body mass index and higher levels of total homocysteine [20], incident clinical stroke, carotid atherosclerosis, incident heart disease and cardiovascular mortality, as well as metabolic syndrome [13]. Larger venular calibers had been shown to be associated with atherosclerosis [27], inflammation [20-22, 27-30], stroke, cardiovascular mortality [13, 31], cigarette smoking $[20,27,32,33]$, and the metabolic syndrome (hyperglycemia, central obesity, and dyslipidemia) [16, 34]. These findings suggested that retinal venular widening may has pleiotropic associations with cardiovascular risk factors and diseases, and was not a specific biomarker for hypertension [35].

There have been some studies on relationship of blood pressure with retinal vessel calibers in children. Mitchell [36] reported that higher childhood blood pressure was associated with retinal arteriolar narrowing but not with retinal venular caliber in children aged 6-8 years. They found that each $10-\mathrm{mmHg}$ increase in systolic blood pressure was associated with narrowing of retinal arterioles by $2.08 \mu \mathrm{m}$ in Sydney children and $1.43 \mu \mathrm{m}$ in Singapore children. In high school students aged 12.7 years, they found that elevated blood pressure was associated with narrower retinal arterioles, and also with wider retinal venules in boys, with each $10-\mathrm{mmHg}$ increase in MABP associated with 2.02- $\mathrm{mm}$ decrease in retinal arteriolar caliber, and $2.19 \mu \mathrm{m}$ increase in CRVE in boys (the Sydney Childhood Eye Study. SCES) [37]. In a later study on Singapore children aged $4 \sim 5$ years, Li et al. [38] found that higher systolic blood pressure was associated with narrower retinal arterioles and wider retinal venules, with each $10-\mathrm{mmHg}$ increase associated with $2.00 \mu \mathrm{m}$ of retinal arteriolar narrowing and $2.51 \mu \mathrm{m}$ of retina venular widening. In 2012, Hanssen examined 578 school children aged $11.1 \pm 0.6$ years from secondary schools in Germany and found that diastolic blood pressure was not only independently associated with arteriolar narrowing, but also with venular narrowing [39]. Imhof found that systolic and diastolic BP were associated with arteriolar narrowing in 391 Switzerland children with an average age of 7.3 years, but they failed to find the association between BP and venular diameter [40].

According to the results of the above studies, we found that just like the roles of retinal venular diameter play on the BP in adults, the relationship between retinal venular diameter and $\mathrm{BP}$ in the childhood population is still in controversy.

Unlike the SCES [37] (The subjects of this study were comparable in age to our research), we didn't catch the finding that higher BP was associated with wider retinal venules in preadolescent boys. We speculated here that there are some possible reasons contributing to the discrepancy between the two results.

First, at present, there were some epidemiological studies on adolescent BP, but these studies had not reached the uniform conclusion related to the gender difference. Some studies showed a higher frequency of elevated BP in males than in females in children population based research [41], but these results differed from those obtained by Rosner B, whose study found that the prevalence of elevated BP significantly increased among girls $(8.2 \%$ versus $12.6 \% ; P=0.007)$, but was only of borderline significance among boys $(15.8 \%$ versus $19.2 \% ; P$ 
Table 4 Subgroup analysis stratified by potential effect modifiers of retinal Arteriolar Diameter with BP, stratified by potential modifiers

\begin{tabular}{|c|c|c|c|c|c|c|c|c|c|}
\hline \multicolumn{3}{|c|}{ Potential Effect Modifiers } & \multirow[t]{2}{*}{$n$} & \multicolumn{6}{|c|}{ Retinal Arteriolar Diameter $(\mu \mathrm{m})$} \\
\hline & & & & Model 1 & $p$ & Model 2 & $P$ & Model 3 & $P$ \\
\hline \multirow[t]{11}{*}{ SBP } & Age & $10+11$ & 70 & $-1.97 \pm 1.66$ & 0.238 & $-0.60 \pm 1.79$ & 0.736 & $-1.28 \pm 1.54$ & 0.411 \\
\hline & & 12 & 1122 & $-3.63 \pm 0.43$ & $<0.01$ & $-3.31 \pm 0.42$ & $<.001$ & $-2.46 \pm 0.39$ & $<.001$ \\
\hline & & $13+14+15$ & 309 & $-2.6 \pm 0.82$ & $<0.01$ & $-2.60 \pm 0.84$ & 0.002 & $-1.98 \pm 0.73$ & 0.007 \\
\hline & Sex & Male & 792 & $-3.1 \pm 0.52$ & $<0.01$ & $-3.41 \pm 0.52$ & $<.001$ & $-2.57 \pm 0.45$ & $<.001$ \\
\hline & & Female & 709 & $-3.05 \pm 0.52$ & $<0.01$ & $-2.73 \pm 0.52$ & $<.001$ & $-2.12 \pm 0.49$ & $<.001$ \\
\hline & BMI & Upper 50\% & 750 & $-2.37 \pm 0.57$ & $<0.01$ & $-2.39 \pm 0.5$ & $<.001$ & $-1.72 \pm 0.49$ & $<.001$ \\
\hline & & Lower 50\% & 751 & $-4.03 \pm 0.55$ & $<0.01$ & $-3.71 \pm 0.52$ & $<.001$ & $-2.89 \pm 0.46$ & $<.001$ \\
\hline & Birth weight & Upper 50\% & 778 & $-3.69 \pm 0.53$ & $<0.01$ & $-3.09 \pm 0.53$ & $<.001$ & $-2.35 \pm 0.48$ & $<.001$ \\
\hline & & Lower 50\% & 723 & $-2.87 \pm 0.51$ & $<0.01$ & $-2.97 \pm 0.52$ & $<.001$ & $-2.28 \pm 0.47$ & $<.001$ \\
\hline & Gestational age & Term & 1372 & $-3.27 \pm 0.39$ & $<0.01$ & $-3.10 \pm 0.39$ & $<.001$ & $-2.33 \pm 0.35$ & $<.001$ \\
\hline & & Preterm & 129 & $-3.06 \pm 1.09$ & $<0.01$ & $-2.46 \pm 1.12$ & 0.03 & $-2.21 \pm 1.02$ & 0.033 \\
\hline \multirow[t]{11}{*}{ DBP } & Age & $10+11$ & 70 & $-1.84 \pm 2.04$ & 0.370 & $-0.78 \pm 2.18$ & 0.722 & $-1.81 \pm 1.88$ & 0.342 \\
\hline & & 12 & 1122 & $-4.85 \pm 0.62$ & $<0.01$ & $-4.74 \pm 0.56$ & $<.001$ & $-3.76 \pm 0.51$ & $<.001$ \\
\hline & & $13+14+15$ & 309 & $-1.35 \pm 1.11$ & $<0.01$ & $-2.27 \pm 1.08$ & 0.037 & $-1.36 \pm 0.95$ & 0.154 \\
\hline & Sex & Male & 792 & $-4.2 \pm 0.74$ & $<0.01$ & $-4.65 \pm 0.69$ & $<.001$ & $-3.67 \pm 0.60$ & $<.001$ \\
\hline & & Female & 709 & $-3.68 \pm 0.72$ & $<0.01$ & $-3.46 \pm 0.67$ & $<.001$ & $-2.79 \pm 0.62$ & $<.001$ \\
\hline & BMI & Upper 50\% & 750 & $-3.33 \pm 0.75$ & $<0.01$ & $-3.73 \pm 0.68$ & $<.001$ & $-3.06 \pm 0.62$ & $<.001$ \\
\hline & & Lower 50\% & 751 & $-4 \pm 0.75$ & $<0.01$ & $-4.30 \pm 0.68$ & $<.001$ & $-3.34 \pm 0.60$ & $<.001$ \\
\hline & Birth weight & Upper 50\% & 778 & $-3.83 \pm 0.73$ & $<0.01$ & $-3.73 \pm 0.66$ & $<.001$ & $-3.01 \pm 0.59$ & $<.001$ \\
\hline & & Lower 50\% & 723 & $-3.92 \pm 0.75$ & $<0.01$ & $-4.31 \pm 0.70$ & $<.001$ & $-3.42 \pm 0.64$ & $<.001$ \\
\hline & Gestational age & Term & 1372 & $-3.89 \pm 0.55$ & $<0.01$ & $-3.95 \pm 0.51$ & $<.001$ & $-3.10 \pm 0.46$ & $<.001$ \\
\hline & & Preterm & 129 & $-3.32 \pm 1.57$ & $<0.01$ & $-4.35 \pm 1.50$ & 0.005 & $-3.69 \pm 1.39$ & 0.009 \\
\hline \multirow[t]{11}{*}{ MABP } & Age & $10+11$ & 70 & $-2.21 \pm 2.03$ & 0.280 & $-0.81 \pm 2.17$ & 0.709 & $-1.83 \pm 1.88$ & 0.334 \\
\hline & & 12 & 1122 & $-5.22 \pm 0.58$ & $<0.01$ & $-5.01 \pm 0.56$ & $<.001$ & $-3.91 \pm 0.51$ & $<.001$ \\
\hline & & $13+14+15$ & 309 & $-2.41 \pm 1.09$ & $<0.01$ & $-3.00 \pm 1.09$ & 0.006 & $-2.04 \pm 0.95$ & 0.034 \\
\hline & Sex & Male & 792 & $-4.40 \pm 0.70$ & $<0.01$ & $-4.91 \pm 0.68$ & $<.001$ & $-3.81 \pm 0.59$ & $<.001$ \\
\hline & & Female & 709 & $-4.21 \pm 0.70$ & $<0.01$ & $-3.89 \pm 0.68$ & $<.001$ & $-3.12 \pm 0.64$ & $<.001$ \\
\hline & BMI & Upper 50\% & 750 & $-3.58 \pm 0.75$ & $<0.01$ & $-3.88 \pm 0.68$ & $<.001$ & $-3.06 \pm 0.63$ & $<.001$ \\
\hline & & Lower 50\% & 751 & $-4.90 \pm 0.73$ & $<0.01$ & $-4.87 \pm 0.68$ & $<.001$ & $-3.81 \pm 0.60$ & $<.001$ \\
\hline & Birth weight & Upper 50\% & 778 & $-4.68 \pm 0.71$ & $<0.01$ & $-4.31 \pm 0.68$ & $<.001$ & $-3.40 \pm 0.61$ & $<.001$ \\
\hline & & Lower 50\% & 723 & $-4.11 \pm 0.70$ & $<0.01$ & $-4.42 \pm 0.68$ & $<.001$ & $-3.49 \pm 0.62$ & $<.001$ \\
\hline & Gestational age & Term & 1372 & $-4.40 \pm 0.53$ & $<0.01$ & $-4.38 \pm 0.51$ & $<.001$ & $-3.39 \pm 0.46$ & $<.001$ \\
\hline & & Preterm & 129 & $-3.98 \pm 1.49$ & $<0.01$ & $-4.23 \pm 1.47$ & 0.005 & $-3.66 \pm 1.35$ & 0.008 \\
\hline
\end{tabular}

Model 1:unadjusted model; Model 2: adjusted for age, gender, axial length, BMI, waist, spherical equivalent, birth weight and gestational age; Model 3: adjusted for fellow vessel diameter additionally. SBP systolic blood pressure, DBP diastolic blood pressure, MABP mean arterial blood pressure. Term means pregnancy lasts longer than 37 weeks, and preterm represents that the duration of pregnancy is less than 37 weeks. Significant $p$ values are bolded

$=0.057$ ), after analyzing a population-based sample of 3248 children in National Health and Nutrition Examination Survey (NHANES) III (1988-1994) and 8388 children in continuous NHANES (1999-2008), aged 8 to 17 years [42]. The female subjects in our study were more frequently shown to have elevated BP compared to males. The SCES did not present whether there was a significant difference between girl and boy blood pressure. If the BP of two genders were basically similar, the difference of the retinal venular caliber maybe associated with other reasons.

Second, in the SCES, with regard to the mechanism underlying the conclusion that higher blood pressure was associated with wider retinal venules in boys, the author deduced that maybe it was because sex hormones had an protective effect on the retinal circulation, as a 
Table 5 Subgroup analysis stratified by potential effect modifiers of retinal Venular Diameter with BP, stratified by potential modifiers

\begin{tabular}{|c|c|c|c|c|c|c|c|c|c|}
\hline \multicolumn{3}{|c|}{ Potential Effect Modifiers } & \multirow[t]{2}{*}{$n$} & \multicolumn{6}{|c|}{ Retinal Venular Diameter $(\mu \mathrm{m})$} \\
\hline & & & & Model 1 & $p$ & Model 2 & P & Model 3 & $P$ \\
\hline \multirow[t]{11}{*}{ SBP } & Age & $10+11$ & 70 & $0.40 \pm 2.16$ & 0.855 & $1.43 \pm 1.99$ & 0.476 & $1.78 \pm 1.71$ & 0.302 \\
\hline & & 12 & 1122 & $-2.1 \pm 0.55$ & $<0.001$ & $-2.52 \pm 0.54$ & $<.001$ & $-0.73 \pm 0.50$ & 0.148 \\
\hline & & $13+14+15$ & 309 & $-0.53 \pm 1.08$ & 0.622 & $-1.61 \pm 1.06$ & 0.129 & $0.02 \pm 0.94$ & 0.986 \\
\hline & Sex & Male & 792 & $-1.12 \pm 0.66$ & 0.092 & $-2.03 \pm 0.65$ & 0.002 & $0.14 \pm 0.57$ & 0.809 \\
\hline & & Female & 709 & $-1.72 \pm 0.69$ & 0.013 & $-2.15 \pm 0.68$ & 0.002 & $-0.85 \pm 0.64$ & 0.186 \\
\hline & BMl & Upper 50\% & 750 & $-1.66 \pm 0.75$ & 0.028 & $-2.11 \pm 0.69$ & 0.002 & $-0.84 \pm 0.64$ & 0.186 \\
\hline & & Lower 50\% & 751 & $-2.67 \pm 0.69$ & $<0.001$ & $-2.13 \pm 0.64$ & 0.001 & $0.06 \pm 0.58$ & 0.923 \\
\hline & Birth weight & Upper 50\% & 778 & $-1.97 \pm 0.68$ & 0.004 & $-2.05 \pm 0.67$ & 0.002 & $-0.27 \pm 0.61$ & 0.654 \\
\hline & & Lower 50\% & 723 & $-1.19 \pm 0.67$ & 0.074 & $-2.06 \pm 0.66$ & 0.002 & $-0.43 \pm 0.61$ & 0.478 \\
\hline & Gestational age & Term & 1372 & $-1.61 \pm 0.5$ & 0.001 & $-2.19 \pm 0.49$ & $<.001$ & $-0.46 \pm 0.45$ & 0.309 \\
\hline & & Preterm & 129 & $-1.13 \pm 1.55$ & 0.467 & $-0.88 \pm 1.64$ & 0.594 & $0.62 \pm 1.53$ & 0.688 \\
\hline \multirow[t]{11}{*}{ DBP } & Age & $10+11$ & 70 & $2.59 \pm 2.64$ & 0.330 & $2.16 \pm 2.42$ & 0.376 & $2.62 \pm 2.08$ & 0.213 \\
\hline & & 12 & 1122 & $-2.42 \pm 0.79$ & 0.002 & $-2.91 \pm 0.72$ & $<.001$ & $-0.31 \pm 0.67$ & 0.648 \\
\hline & & $13+14+15$ & 309 & $0.3 \pm 1.45$ & 0.838 & $-2.33 \pm 1.36$ & 0.089 & $-0.92 \pm 1.20$ & 0.442 \\
\hline & Sex & Male & 792 & $-1.11 \pm 0.94$ & 0.239 & $-2.38 \pm 0.86$ & 0.006 & $0.60 \pm 0.76$ & 0.433 \\
\hline & & Female & 709 & $-1.96 \pm 0.96$ & 0.042 & $-2.35 \pm 0.86$ & 0.007 & $-0.69 \pm 0.82$ & 0.4 \\
\hline & BMl & Upper 50\% & 750 & $-1.42 \pm 0.99$ & 0.151 & $-2.12 \pm 0.89$ & 0.017 & $-0.10 \pm 0.82$ & 0.907 \\
\hline & & Lower 50\% & 751 & $-2.11 \pm 0.95$ & 0.026 & $-2.46 \pm 0.84$ & 0.004 & $0.07 \pm 0.76$ & 0.93 \\
\hline & Birth weight & Upper 50\% & 778 & $-1.47 \pm 0.93$ & 0.112 & $-1.98 \pm 0.84$ & 0.018 & $0.18 \pm 0.76$ & 0.811 \\
\hline & & Lower 50\% & 723 & $-1.48 \pm 0.98$ & 0.132 & $-2.65 \pm 0.90$ & 0.003 & $-0.28 \pm 0.83$ & 0.733 \\
\hline & Gestational age & Term & 1372 & $-1.59 \pm 0.71$ & 0.024 & $-2.37 \pm 0.64$ & $<.001$ & $-0.15 \pm 0.58$ & 0.798 \\
\hline & & Preterm & 129 & $-0.02 \pm 2.2$ & 0.994 & $-2.43 \pm 2.23$ & 0.278 & $0.18 \pm 2.12$ & 0.931 \\
\hline \multirow[t]{11}{*}{ MABP } & Age & $10+11$ & 70 & $1.92 \pm 2.65$ & 0.469 & $2.13 \pm 2.41$ & 0.38 & $2.61 \pm 2.07$ & 0.213 \\
\hline & & 12 & 1122 & $-2.75 \pm 0.76$ & $<0.001$ & $-3.32 \pm 0.71$ & $<.001$ & $-0.59 \pm 0.67$ & 0.38 \\
\hline & & $13+14+15$ & 309 & $-0.12 \pm 1.43$ & 0.933 & $-2.48 \pm 1.37$ & 0.072 & $-0.62 \pm 1.21$ & 0.609 \\
\hline & Sex & Male & 792 & $-1.34 \pm 0.89$ & 0.133 & $-2.68 \pm 0.85$ & 0.002 & $0.47 \pm 0.75$ & 0.535 \\
\hline & & Female & 709 & $-2.25 \pm 0.94$ & 0.017 & $-2.76 \pm 0.88$ & 0.002 & $-0.90 \pm 0.84$ & 0.284 \\
\hline & BMl & Upper 50\% & 750 & $-1.89 \pm 0.99$ & 0.056 & $-2.63 \pm 0.89$ & 0.003 & $-0.55 \pm 0.83$ & 0.513 \\
\hline & & Lower 50\% & 751 & $-2.85 \pm 0.93$ & 0.002 & $-2.74 \pm 0.83$ & 0.001 & $0.13 \pm 0.76$ & 0.868 \\
\hline & Birth weight & Upper 50\% & 778 & $-2.13 \pm 0.91$ & 0.020 & $-2.52 \pm 0.86$ & 0.003 & $-0.02 \pm 0.78$ & 0.978 \\
\hline & & Lower 50\% & 723 & $-1.55 \pm 0.92$ & 0.093 & $-2.80 \pm 0.87$ & 0.001 & $-0.38 \pm 0.81$ & 0.643 \\
\hline & Gestational age & Term & 1372 & $-1.94 \pm 0.68$ & 0.004 & $-2.78 \pm 0.64$ & $<.001$ & $-0.33 \pm 0.59$ & 0.577 \\
\hline & & Preterm & 129 & $-0.72 \pm 2.13$ & 0.736 & $-2.07 \pm 2.18$ & 0.345 & $0.49 \pm 2.07$ & 0.812 \\
\hline
\end{tabular}

Model 1:unadjusted model; Model 2: adjusted for age, gender, axial length, BMI, waist, spherical equivalent, birth weight and gestational age; Model 3: adjusted for fellow vessel diameter additionally. SBP systolic blood pressure, DBP diastolic blood pressure, MABP mean arterial blood pressure. Term means pregnancy lasts longer than 37 weeks, and preterm represents that the duration of pregnancy is less than 37 weeks.Significant $p$ values are bolded

proportion of girls would have commenced puberty. But it was interesting that Zou found that in 76,869 Chinese girls, the rate of high blood pressure in menstruation group from 11 to 13 years was significant higher than that in the same age group of non-menstruation [43]. Similarly, there was conflicting evidence that hormone treatment could effectively reduce the risk of coronary heart disease, data from two large randomized clinical trials, the women's health initiative (WHI) [44] and the heart estrogen and progestin replacement study (HERS) [45], found an increase in cardiovascular incidences in women taking hormone replacement therapy. In some adult population based studies, estrogen replacement therapy was found to be associated with narrower retinal arteriolar and venular calibers [46], independent of blood pressure and other vascular factors, but other 
Table 6 Subgroup analysis stratified by potential effect modifiers of AVR with BP, stratified by potential modifiers

\begin{tabular}{|c|c|c|c|c|c|c|c|}
\hline \multicolumn{3}{|c|}{ Potential Effect Modifiers } & \multirow[t]{2}{*}{$n$} & \multicolumn{4}{|l|}{ AVR } \\
\hline & & & & Model 1 & p & Model 2 & $P$ \\
\hline \multirow[t]{11}{*}{ SBP } & Age & $10+11$ & 70 & $-0.010 \pm 0.006$ & 0.118 & $-0.007 \pm 0.007$ & 0.37 \\
\hline & & 12 & 1122 & $-0.010 \pm 0.002$ & $<.001$ & $-0.007 \pm 0.002$ & $<.001$ \\
\hline & & $13+14+15$ & 309 & $-0.010 \pm 0.003$ & 0.002 & $-0.007 \pm 0.004$ & 0.05 \\
\hline & Sex & Male & 792 & $-0.010 \pm 0.002$ & $<.001$ & $-0.009 \pm 0.002$ & $<.001$ \\
\hline & & Female & 709 & $-0.009 \pm 0.006$ & $<.001$ & $-0.006 \pm 0.002$ & 0.02 \\
\hline & BMI & Upper 50\% & 750 & $-0.006 \pm 0.002$ & 0.020 & $-0.005 \pm 0.002$ & 0.06 \\
\hline & & Lower 50\% & 751 & $-0.010 \pm 0.002$ & $<.001$ & $-0.010 \pm 0.002$ & $<.001$ \\
\hline & Birth weight & Upper 50\% & 778 & $-0.010 \pm 0.002$ & $<.001$ & $-0.007 \pm 0.002$ & 0.001 \\
\hline & & Lower 50\% & 723 & $-0.010 \pm 0.002$ & $<.001$ & $-0.007 \pm 0.002$ & 0.002 \\
\hline & Gestational age & Term & 1372 & $-0.010 \pm 0.002$ & $<.001$ & $-0.007 \pm 0.001$ & $<.001$ \\
\hline & & Preterm & 129 & $-0.010 \pm 0.004$ & 0.035 & $-0.008 \pm 0.007$ & 0.015 \\
\hline \multirow[t]{11}{*}{ DBP } & Age & $10+11$ & 70 & $-0.016 \pm 0.008$ & 0.046 & $-0.009 \pm 0.009$ & 0.314 \\
\hline & & 12 & 1122 & $-0.015 \pm 0.002$ & $<.001$ & $-0.013 \pm 0.002$ & $<.001$ \\
\hline & & $13+14+15$ & 309 & $-0.007 \pm 0.005$ & 0.136 & $-0.003 \pm 0.004$ & 0.493 \\
\hline & Sex & Male & 792 & $-0.016 \pm 0.003$ & $<.001$ & $-0.014 \pm 0.003$ & $<.001$ \\
\hline & & Female & 709 & $-0.011 \pm 0.006$ & 0.003 & $-0.009 \pm 0.003$ & 0.009 \\
\hline & BMI & Upper 50\% & 750 & $-0.011 \pm 0.003$ & $<.001$ & $-0.011 \pm 0.003$ & $<.001$ \\
\hline & & Lower 50\% & 751 & $-0.012 \pm 0.003$ & $<.001$ & $-0.012 \pm 0.003$ & $<.001$ \\
\hline & Birth weight & Upper 50\% & 778 & $-0.013 \pm 0.019$ & $<.001$ & $-0.011 \pm 0.003$ & $<.001$ \\
\hline & & Lower 50\% & 723 & $-0.013 \pm 0.003$ & $<.001$ & $-0.012 \pm 0.003$ & $<.001$ \\
\hline & Gestational age & Term & 1372 & $-0.013 \pm 0.002$ & $<.001$ & $-0.011 \pm 0.002$ & $<.001$ \\
\hline & & Preterm & 129 & $-0.015 \pm 0.007$ & 0.03 & $-0.012 \pm 0.007$ & 0.137 \\
\hline \multirow[t]{11}{*}{ MABP } & Age & $10+11$ & 70 & $-0.016 \pm 0.008$ & 0.048 & $-0.009 \pm 0.009$ & 0.302 \\
\hline & & 12 & 1122 & $-0.015 \pm 0.002$ & $<.001$ & $-0.013 \pm 0.002$ & $<.001$ \\
\hline & & $13+14+15$ & 309 & $-0.010 \pm 0.005$ & 0.02 & $-0.006 \pm 0.005$ & 0.192 \\
\hline & Sex & Male & 792 & $-0.016 \pm 0.002$ & $<.001$ & $-0.014 \pm 0.002$ & $<.001$ \\
\hline & & Female & 709 & $-0.013 \pm 0.003$ & $<.001$ & $-0.009 \pm 0.003$ & 0.005 \\
\hline & $\mathrm{BMl}$ & Upper 50\% & 750 & $-0.010 \pm 0.003$ & $<.001$ & $-0.010 \pm 0.003$ & 0.002 \\
\hline & & Lower 50\% & 751 & $-0.014 \pm 0.003$ & $<.001$ & $-0.012 \pm 0.003$ & $<.001$ \\
\hline & Birth weight & Upper 50\% & 778 & $-0.015 \pm 0.003$ & $<.001$ & $-0.012 \pm 0.003$ & $<.001$ \\
\hline & & Lower 50\% & 723 & $-0.014 \pm 0.003$ & $<.001$ & $-0.007 \pm 0.007$ & $<.001$ \\
\hline & Gestational age & Term & 1372 & $-0.014 \pm 0.002$ & $<.001$ & $-0.012 \pm 0.002$ & $<.001$ \\
\hline & & Preterm & 129 & $-0.016 \pm 0.006$ & 0.018 & $-0.012 \pm 0.007$ & 0.108 \\
\hline
\end{tabular}

Model 1:unadjusted model; Model 2: adjusted for age, gender, axial length, BMI, waist, spherical equivalent, birth weight and gestational age. SBP systolic blood pressure, $D B P$ diastolic blood pressure, MABP mean arterial blood pressure, $A V R$ arteriolar to venular ratio. Term means pregnancy lasts longer than 37 weeks, and preterm represents that the duration of pregnancy is less than 37 weeks.Significant $p$ values are bolded

researchers failed to found relationship between hormonal status in women and retinal vessel caliber [22]. Therefore, more and further researches were needed to acquire a greater depth of understanding on whether the hormone would have an effect on vessel diameter and would produce what kind of impact.

Third, the prevalence of child obesity is increasing rapidly worldwide, and the BMI may play an active role in the result of association of blood pressure and CRVE. Although a lot of literatures showed that the BMI was higher among boys than that of girls [47], Cole TJ reported that in population of 2-17 years of age, the prevalence of overweight is $25 \%$ in girls and $27 \%$ in boys, and obesity is 7 and 9\% in males and females respectively [48]. In our studies, girls had a significantly higher BMI than boys $(P<0.0001)$. Obesity might influence the 
change of blood pressure by some mechanisms such as glomerular and tubular effects, and some of these mechanisms are sex dependent [49]. In the SCES research, they did not present the particular values of BMI for boys and girls. If the boys were more likely overweight just like that in other studies, they had a better chance to get wider venule than the same-aged girls. Although the BMI had been adjusted, high BMI might accompany by some possible physical abnormalities such as dyslipidemia, hyperglycemia and inflammation, which could result in wider retinal venules simultaneously.

Forth, lack of regular moderate-to-vigorous intensity physical activity is a well-known risk factor for cardiovascular disease, increasingly amount of studies have been focusing on the relationship between physical activity and retinal microcirculation and cardiovascular diseases [50]. Physical activity has been shown to be able to improve coronary endothelial function, reduce systemic blood pressure and improve early markers of atherosclerosis in pre-pubertal obese children. The association of higher levels of physical activity with better retinal vessel health have been demonstrated in adults as well as in children population [39, 51-53]. Before and during adolescence, girls usually undergo a lower level of physical exercise and greater decline in active physical activity than boys [54], which might explain the difference to some extent. Correspondingly, in our study, girls had higher waist circumference and BMI, which might result from insufficiency of physical activity compared with boys.

In addition to the reasons analyzed above, the association between blood pressure and retinal venular caliber might be affected by other factors such as smoking status [55], genetic and sex determinants, as well as ethnic differences. In summary, the association between BP and retinal venular caliber is a result of the interplay of many complicated reasons, maybe elevated blood pressure was associated with wider retinal venules in preadolescent boys, but due to the influence by comprehensive factors, the change was not significantly manifest in our study.

In the past, researchers had generally attributed a lower arteriolar-to-venular ratio (AVR) to generalized arteriolar narrowing and suggested that this ratio may provide information that would predict incident cardiovascular diseases. But with the advent of semi-automatic examination, it makes it possible to measure arteries and veins in retinal fundus separately. Since 2004, Ikram [27] and other researchers confirmed that elevated blood pressures were associated with smaller arteriolar diameters, but larger venular diameters were related to atherosclerosis, inflammation, and cholesterol levels. Hence, the idea that the AVR overall reflects generalized arteriolar narrowing should be reevaluated by taking into account the separate arteriolar and venular diameters. Therefore, many scholars suggested that arteriolar and venular diameters should be examined separately, especially in etiologic research [23]. In our study, we found that increasing blood pressure was significantly associated with narrowing retinal arteriolar caliber and smaller AVR, but not with retinal venular caliber.

Our results once again stressed the necessity of additional adjustment of concomitant vessels. We found a relationship between higher SBP and smaller CRVE, however, when CRAE was added to the final multivariate-adjusted model (model 3), the relationship between SBP and CRVE became nonsignificant, and further adjustment of the caliber of the CRVE diminished the reduction magnitude of CRAE when $\mathrm{BP}$ increased, suggesting the possibility of a confounding effect of fellow vessel caliber on this association. A significant association between narrower venular caliber and hypertension was initially reported in the Rotterdam Eye Study [23], but this result was diminished after additional adjustment with retinal arteriolar caliber, and the same conclusion was obtained by Myers [22]. The difference of the results illustrated the importance of correcting concomitant vessels.

Strengths of this study include its random cluster sample of a large number of representative healthy schoolchildren. The samples were free of influences from systemic disease processes or eye diseases on retinal vessel measurements. We also used a previously validated standardized protocol of quantitative retinal imaging program for retinal vessel measurement. However, some potential limitations of our study demand consideration. First, the study design is cross-sectional and does not provide temporal information on the associations. Second, the possible selection bias giving rise from the exclusion of students by ineligibility and ungradable retinal photographs may play a part on the real association between BP and retinal vessel diameters. Finally, we failed to acquire further information from our samples such as smoking status, family history, blood lipid levels, blood glucose, which may have an impact on the results.

In conclusion, this study shows that in population of 12-year-old Chinese children, increasing blood pressure was significantly associated with narrower retinal arteriolar caliber but not with retinal venular caliber, and possible confounding factors such as sex et al. had no effect on the relationship between $\mathrm{BP}$ and retinal vessel diameters. This finding provided further insight into the relationship of elevated $\mathrm{BP}$ on the microcirculation that occurs in early life. The association of wider retinal venular caliber and hypertension has not yet been consistently found, which should remain one of our highest research priorities. 


\section{Abbreviations}

BMl: Body mass index; BP: Blood pressure; CRAE: Central retinal arteriolar equivalents; CRVE: Central retinal venular equivalents; DBP: Diastolic blood pressure; MABP: Mean arterial blood pressure; SBP: Systolic blood pressure

\section{Acknowledgements}

The authors thank the support from the Anyang city government for helping to organize the survey. We acknowledge the University of Wisconsin Fundus Photograph Reading Center and Nicola Ferrier of the School of Engineering at University of Wisconsin for providing the software of measuring retinal vessels calibers.

\section{Availability of data and materials}

The datasets used and/or analysed during the current study are available from the corresponding author on reasonable request.

\section{Authors' contributions}

$\mathrm{YH}$ performed all of the retinal vessel pictures and wrote the whole manuscript. S-ML designed the study and supervised the progress of the entire study. M-TK, L-RL and HL participated in the design of the experiment, data collection and analysis. S-FW and A-RR undertook the statistical analysis of sample data. NW designed the study, supervised the progress of the entire study, revised the manuscript and finally agreed to submission. All authors read and approved the final manuscript.

\section{Ethics approval and consent to participate}

Ethics approval was obtained from the institutional review board of Beijing Tongren Hospital, Capital Medical University, and followed the tenets of the declaration of Helsinki. Informed written consent was obtained from at least one parent. Verbal assent was obtained from each child.

\section{Competing interests}

All of the authors declare that they have no competing interests.

\section{Publisher's Note}

Springer Nature remains neutral with regard to jurisdictional claims in published maps and institutional affiliations.

\section{Author details}

${ }^{1}$ Beijing Tongren Eye Center, Beijing Tongren Hospital, Beijing Ophthalmology \& Visual Science Key Lab, Beijing Institute of Ophthalmology, Capital Medical University, Beijing, China. ${ }^{2}$ Anyang Eye Hospital, Anyang, Henan, China.

\section{Received: 10 September 2017 Accepted: 25 May 2018}

Published online: 04 June 2018

\section{References}

1. Gunn R. Opthalmocsopic evidence of (1) arterial changes associated with chronic renal diseases and (2) of increased arterial tension. Trans Ophthalmol Soc UK. 1892;12:124-5.

2. Schneider R, Rademacher M, Wolf S. Lacunar infarcts and white matter attenuation. Ophthalmologic and microcirculatory aspects of the pathophysiology. Stroke. 1993;24(12):1874-9.

3. Hubbard LD, Brothers RJ, King WN, Clegg LX, Klein R, Cooper LS, Sharrett AR, Davis MD, Cai J. Methods for evaluation of retinal microvascular abnormalities associated with hypertension/sclerosis in the atherosclerosis risk in communities study. Ophthalmology. 1999;106(12):2269-80.

4. Seidelmann SB, Claggett B, Bravo PE, Gupta A, Farhad H, Klein BE, Klein R, Di Carli M, Solomon SD. Retinal vessel calibers in predicting long-term cardiovascular outcomes: the atherosclerosis risk in communities study. Circulation. 2016;134(18):1328-38.

5. Rizzoni D, Muiesan ML. Retinal vascular caliber and the development of hypertension: a meta-analysis of individual participant data. J Hypertens. 2014;32(2):225-7

6. Gopinath B, Chiha J, Plant AJ, Thiagalingam A, Burlutsky G, Kovoor P, Liew G, Mitchell P. Associations between retinal microvascular structure and the severity and extent of coronary artery disease. Atherosclerosis. 2014;236(1):25-30

7. Kawasaki R, Xie J, Cheung N, Lamoureux E, Klein R, Klein BE, Cotch MF, Sharrett AR, Shea S, Wong TY. Retinal microvascular signs and risk of stroke: the multi-ethnic study of atherosclerosis (MESA). Stroke. 2012; 43(12):3245-51.

8. Hughes AD, Falaschetti E, Witt N, Wijetunge $S$, Thom SA, Tillin T, Aldington SJ, Chaturvedi N. Association of Retinopathy and Retinal Microvascular Abnormalities with Stroke and cerebrovascular disease. Stroke. 2016;47(11): 2862-4

9. Lim LS, Cheung CY, Sabanayagam C, Lim SC, Tai ES, Huang L, Wong TY. Structural changes in the retinal microvasculature and renal function. Invest Ophthalmol Vis Sci. 2013;54(4):2970-6.

10. Karatzi K, Protogerou AD, Moschonis G, Tsirimiagou C, Androutsos O, Chrousos GP, Lionis C, Manios Y. Prevalence of hypertension and hypertension phenotypes by age and gender among schoolchildren in Greece: the healthy growth study. Atherosclerosis. 2017;259:128-33.

11. Liang YJ, Xi B, Hu YH, Wang C, Liu JT, Yan YK, Xu T, Wang RQ. Trends in blood pressure and hypertension among Chinese children and adolescents: China health and nutrition surveys 1991-2004. Blood Press. 2011;20(1):45-53.

12. Li SM, Liu LR, Li SY, Ji YZ, Fu J, Wang Y, Li H, Zhu BD, Yang Z, Li L, et al. Design, methodology and baseline data of a school-based cohort study in Central China: the Anyang childhood eye study. Ophthalmic Epidemiol. 2013;20(6):348-59

13. Henderson AD, Bruce BB, Newman NJ, Biousse V. Hypertension-related eye abnormalities and the risk of stroke. Rev Neurol Dis. 2011;8(1-2):1-9.

14. Wong TY, Hubbard LD, Klein R, Marino EK, Kronmal R, Sharrett AR, Siscovick DS, Burke G, Tielsch JM. Retinal microvascular abnormalities and blood pressure in older people: the cardiovascular health study. Br J Ophthalmol. 2002;86(9):1007-13.

15. Sharrett AR, Hubbard LD, Cooper LS, Sorlie PD, Brothers RJ, Nieto FJ, Pinsky JL, Klein R. Retinal arteriolar diameters and elevated blood pressure: the atherosclerosis risk in communities study. Am J Epidemiol. 1999:150(3):263-70.

16. Jeganathan VS, Sabanayagam C, Tai ES, Lee J, Sun C, Kawasaki R, Nagarajan S, Huey-Shi MH, Sandar M, Wong TY. Effect of blood pressure on the retinal vasculature in a multi-ethnic Asian population. Hypertension research official journal of the Japanese Society of Hypertension. 2009:32(11):975-82.

17. Sun C, Liew G, Wang JJ, Mitchell P, Saw SM, Aung T, Tai ES, Wong TY. Retinal vascular caliber, blood pressure, and cardiovascular risk factors in an Asian population: the Singapore Malay eye study. Invest Ophthalmol Vis Sci. 2008:49(5):1784-90.

18. Kawasaki R, Cheung N, Wang JJ, Klein R, Klein BE, Cotch MF, Sharrett AR, Shea S, Islam FA, Wong TY. Retinal vessel diameters and risk of hypertension: the multiethnic study of atherosclerosis. J Hypertens. 2009;27(12):2386-93.

19. Wong TY, Klein R, Klein BE, Meuer SM, Hubbard LD. Retinal vessel diameters and their associations with age and blood pressure. Invest Ophthalmol Vis Sci. 2003:44(11):4644-50

20. Wong TY, Islam FM, Klein R, Klein BE, Cotch MF, Castro C, Sharrett AR, Shahar E. Retinal vascular caliber, cardiovascular risk factors, and inflammation: the multi-ethnic study of atherosclerosis (MESA). Invest Ophthalmol Vis Sci. 2006;47(6):2341-50.

21. Liew G, Sharrett AR, Wang JJ, Klein R, Klein BE, Mitchell P, Wong TY. Relative importance of systemic determinants of retinal arteriolar and venular caliber: the atherosclerosis risk in communities study. Archives of ophthalmology (Chicago, III : 1960). 2008;126(10):1404-10.

22. Myers CE, Klein R, Knudtson MD, Lee KE, Gangnon R, Wong TY, Klein BE. Determinants of retinal venular diameter: the beaver dam eye study. Ophthalmology. 2012;119(12):2563-71.

23. Ikram MK, Witteman JC, Vingerling JR, Breteler MM, Hofman A, de Jong PT. Retinal vessel diameters and risk of hypertension: the Rotterdam study. Hypertension. 2006;47(2):189-94.

24. Tanabe Y, Kawasaki R, Wang JJ, Wong TY, Mitchell P, Daimon M, Oizumi T, Kato T, Kawata S, Kayama T, et al. Retinal arteriolar narrowing predicts 5-year risk of hypertension in Japanese people: the Funagata study. Microcirculation (New York, NY : 1994). 2010;17(2):94-102.

25. Wang JJ, Rochtchina E, Liew G, Tan AG, Wong TY, Leeder SR, Smith W, Shankar A, Mitchell P. The long-term relation among retinal arteriolar narrowing, blood pressure, and incident severe hypertension. Am J Epidemiol. 2008;168(1):80-8.

26. Leung H, Wang JJ, Rochtchina E, Tan AG, Wong TY, Klein R, Hubbard LD, Mitchell P. Relationships between age, blood pressure, and retinal vessel diameters in an older population. Invest Ophthalmol Vis Sci. 2003:44(7):2900-4.

27. Ikram MK, de Jong FJ, Vingerling JR, Witteman JC, Hofman A, Breteler MM de Jong PT. Are retinal arteriolar or venular diameters associated with 
markers for cardiovascular disorders? The Rotterdam study. Invest Ophthalmol Vis Sci. 2004;45(7):2129-34.

28. Wong TY, Duncan BB, Golden SH, Klein R, Couper DJ, Klein BE, Hubbard LD, Sharrett AR, Schmidt MI. Associations between the metabolic syndrome and retinal microvascular signs: the atherosclerosis risk in communities study. Invest Ophthalmol Vis Sci. 2004:45(9):2949-54.

29. de Jong FJ, Ikram MK, Witteman JC, Hofman A, de Jong PT, Breteler MM Retinal vessel diameters and the role of inflammation in cerebrovascular disease. Ann Neurol. 2007;61(5):491-5.

30. Yim-Lui Cheung C, Wong TY, Lamoureux EL, Sabanayagam C, Li J, Lee J, Tai ES. C-reactive protein and retinal microvascular caliber in a multiethnic asian population. Am J Epidemiol. 2010;171(2):206-13.

31. McGeechan K, Liew G, Macaskill P, Irwig L, Klein R, Klein BE, Wang J J, Mitchell $P$, Vingerling JR, de Jong PT, et al. Prediction of incident stroke events based on retinal vessel caliber: a systematic review and individualparticipant meta-analysis. Am J Epidemiol. 2009;170(11):1323-32.

32. Klein $\mathrm{R}$, Klein $\mathrm{BE}$, Knudtson MD, Wong TY, Tsai MY. Are inflammatory factors related to retinal vessel caliber? The beaver dam eye study. Archives of ophthalmology (Chicago, III : 1960). 2006;124(1):87-94.

33. Kifley A, Liew G, Wang JJ, Kaushik S, Smith W, Wong TY, Mitchell P. Longterm effects of smoking on retinal microvascular caliber. Am J Epidemiol. 2007;166(11):1288-97.

34. Nguyen TT, Wang JJ, Sharrett AR, Islam FM, Klein R, Klein BE, Cotch MF, Wong TY. Relationship of retinal vascular caliber with diabetes and retinopathy: the multi-ethnic study of atherosclerosis (MESA). Diabetes Care. 2008;31(3):544-9.

35. Ding J, Wai KL, McGeechan K, Ikram MK, Kawasaki R, Xie J, Klein R, Klein BB, Cotch MF, Wang JJ, et al. Retinal vascular caliber and the development of hypertension: a meta-analysis of individual participant data. J Hypertens. 2014:32(2):207-15.

36. Mitchell P, Cheung N, de Haseth K, Taylor B, Rochtchina E, Islam FM, Wang $J$ J, Saw SM, Wong TY. Blood pressure and retinal arteriolar narrowing in children. Hypertension. 2007;49(5):1156-62.

37. Gopinath B, Baur LA, Wang JJ, Teber E, Liew G, Cheung N, Wong TY, Mitchell $P$. Blood pressure is associated with retinal vessel signs in preadolescent children. J Hypertens. 2010;28(7):1406-12.

38. Li LJ, Cheung CY, Liu Y, Chia A, Selvaraj P, Lin XY, Chan YM, Varma R, Mitchell P, Wong TY, et al. Influence of blood pressure on retinal vascular caliber in young children. Ophthalmology. 2011;118(7):1459-65.

39. Hanssen H, Siegrist M, Neidig M, Renner A, Birzele P, Siclovan A, Blume K, Lammel C, Haller B, Schmidt-Trucksass A, et al. Retinal vessel diameter, obesity and metabolic risk factors in school children (JuvenTUM 3). Atherosclerosis. 2012;221(1):242-8.

40. Imhof K, Zahner L, Schmidt-Trucksass A, Hanssen H. Association of body composition and blood pressure categories with retinal vessel diameters in primary school children. Hypertension research : official journal of the Japanese Society of Hypertension. 2016;39(6):423-9.

41. Reed KE, Warburton DE, McKay HA. Determining cardiovascular disease risk in elementary school children: developing a healthy heart score. Journal of sports science \& medicine. 2007;6(1):142-8.

42. Rosner B, Cook NR, Daniels S, Falkner B. Childhood blood pressure trends and risk factors for high blood pressure: the NHANES experience 1988-2008. Hypertension. 2013;62(2):247-54.

43. Zou ZY, Ma J, Wang HJ, Fu LG, Dong B, Yang YD. Association between early age at menarche and blood pressure in Chinese girls aged 7 to 17 years. Zhonghua yu fang yi xue za zhi [Chinese journal of preventive medicine]. 2013;47(8):726-30.

44. Rossouw JE, Anderson GL, Prentice RL, LaCroix AZ, Kooperberg C, Stefanick ML, Jackson RD, Beresford SA, Howard BV, Johnson KC, et al. Risks and benefits of estrogen plus progestin in healthy postmenopausal women: principal results from the Women's Health Initiative randomized controlled trial. Jama. 2002;288(3):321-33.

45. Hulley S, Grady D, Bush T, Furberg C, Herrington D, Riggs B, Vittinghoff E. Randomized trial of estrogen plus progestin for secondary prevention of coronary heart disease in postmenopausal women. Heart and estrogen/progestin replacement study (HERS) research group. Jama. 1998;280(7):605-13.

46. Wong TY, Knudtson MD, Klein BE, Klein R, Hubbard LD. Estrogen replacement therapy and retinal vascular caliber. Ophthalmology. 2005; 112(4):553-8.

47. Kelishadi R, Heshmat R, Motlagh ME, Majdzadeh R, Keramatian K, Qorbani M, Taslimi M, Aminaee T, Ardalan G, Poursafa P, et al. Methodology and early findings of the third survey of CASPIAN study: a National School-based Surveillance of Students' high risk behaviors. International journal of preventive medicine. 2012;3(6):394-401.

48. Cole TJ, Bellizzi MC, Flegal KM, Dietz WH. Establishing a standard definition for child overweight and obesity worldwide: international survey. BMJ (Clinical research ed). 2000;320(7244):1240-3.

49. Regitz-Zagrosek V, Lehmkuhl E, Weickert MO. Gender differences in the metabolic syndrome and their role for cardiovascular disease. Clin. Res. Cardiol.: official journal of the German Cardiac Society. 2006;95(3):136-47.

50. Gerber M, Endes K, Herrmann C, Colledge F, Brand S, Donath L, Faude O, Puhse $U$, Hanssen $H$, Zahner L. Does physical fitness buffer the relationship between psychosocial stress, retinal vessel diameters, and blood pressure among primary schoolchildren? Biomed Res Int. 2016;2016:6340431.

51. Tikellis G, Anuradha S, Klein R, Wong TY. Association between physical activity and retinal microvascular signs: the atherosclerosis risk in communities (ARIC) study. Microcirculation (New York, NY : 1994). 2010 17(5):381-93.

52. Anuradha S, Healy GN, Dunstan DW, Klein R, Klein BE, Cotch MF, Wong TY, Owen N. Physical activity, television viewing time, and retinal microvascular caliber: the multi-ethnic study of atherosclerosis. Am J Epidemiol. 2011; 173(5):518-25.

53. Imhof K, Zahner L, Schmidt-Trucksass A, Faude O, Hanssen H. Influence of physical fitness and activity behavior on retinal vessel diameters in primary schoolchildren. Scand J Med Sci Sports. 2016;26(7):731-8.

54. Nader PR. National Institute of child H, human development study of early child C, youth development $\mathrm{N}$ : frequency and intensity of activity of third-grade children in physical education. Arch Pediatr Adolesc Med. 2003;157(2):185-90.

55. Karp I, O'Loughlin J, Paradis G, Hanley J, Difranza J. Smoking trajectories of adolescent novice smokers in a longitudinal study of tobacco use. Ann Epidemiol. 2005;15(6):445-52

\section{Ready to submit your research? Choose BMC and benefit from:}

- fast, convenient online submission

- thorough peer review by experienced researchers in your field

- rapid publication on acceptance

- support for research data, including large and complex data types

- gold Open Access which fosters wider collaboration and increased citations

- maximum visibility for your research: over $100 \mathrm{M}$ website views per year

At BMC, research is always in progress.

Learn more biomedcentral.com/submissions 